\title{
Paulo Freire: la pedagogía latinoamericana dialoga con la esperanza
}

\author{
Marcela Gómez Sollano*
}

El objetivo del presente artículo es abrir un espacio de reflexión para situar la importancia y alcances que la palabra esperanza tiene en la obra de Paulo Freire, particularmente por lo que ésta representa para el sujeto cuando se enfrenta a situaciones límite. Dicha reflexión adquiere relevancia en el momento actual en el que como humanidad nos hemos visto profundamente afectados por las dinámicas de confinamiento y dislocación del entramado social, económico y educativo que trajo consigo la pandemia sanitaria provocada por la COVID-19. Esto plantea, entre otras cuestiones, que los sujetos participantes de un determinado entramado político-pedagógico, dialógico, crítico y problematizador se aventuren a lo posible que, como invención, abre las posibilidades de la creación que la praxis plantea como síntesis entre teoría-palabra y acción. Su compleja e incierta articulación con el sueño del educador constituye una de las cuestiones que Freire legó a la pedagogía latinoamericana.
Palabras clave

Esperanza

Situaciones límite

Pedagogía

latinoamericana

Inédito viable

Vínculo pedagógico

* Profesora titular de tiempo completo de la Facultad de Filosofía y Letras de la Universidad Nacional Autónoma de México (UNAM) (México). Doctora en Pedagogía. Líneas de investigación: formación de sujetos de la educación en América Latina; conformación teórico-epistemológica del campo de la pedagogía. Publicaciones recientes: (2019), La disputa por la educación. Tensiones y articulaciones en el marco de las reformas educativas en México y América Latina, México, DGAPA/UNAM-FFyL; (2018, con Adriana Puiggrós, coords.), Fuentes sobre alternativas pedagógicas populares en América Latina, Buenos Aires, Universidad de Buenos Aires. CE: margom@unam.mx 
De las múltiples aristas que se anidan con fuerza en la obra que el comprometido e incansable educador brasileño Paulo Reglus Neves Freire (19211997) nos legó como herencia de su ideario político-pedagógico, hay una que me ha acompañado en el día con día de mi quehacer como profesora, particularmente en este tiempo histórico que nos ha colocado como humanidad frente a límites insospechados. Al estar en los bordes de la cotidianidad, de la coyuntura, esta palabra adquiere dimensiones impensadas. El gran pensador latinoamericano nacido en Recife, Pernambuco, provincia de la región noreste del Brasil, un 19 de septiembre de 1921, la hizo jugar de múltiples maneras para que la educación y los procesos de alfabetización, en su praxis transformadora, no perdieran la brújula del por venir en la lucha de los pueblos por la justicia y su emancipación respecto de la opresión. Con nueve letras que se agolpan con tan sólo unirlas, la palabra esperanza alcanza dimensiones no previstas porque hace que la vida de las personas, sobre todo de aquéllas que, en nuestro continente, cargan en sus cuerpos situaciones que las colocan en los bordes de la muerte y de la sobrevivencia, vaya más allá del diario existir.

Este 2021, declarado el año de Freire, ha sido testigo de la multiplicidad de voces que desde diversas latitudes de nuestra América y de otras regiones del mundo, abrieron las pantallas y tomaron la palabra para hacer de su obra un testimonio vivo que no sólo ha nutrido y da cuerpo a la pedagogía latinoamericana, sino que muestra su potencial cuando el texto freireano se lee al calor de las circunstancias que produjeron la acción político-humanística y su escritura (Rodríguez, 2015), así como en el hecho de recrearla y potenciarla (Santana et al., 2021). Esto implica la presencia y acción de un sujeto activo que sabe encarar con compromiso y valentía el hecho de hacer del conocimiento, del saber, de la experiencia y de la praxis un ejercicio que dota de sentido a la acción; que amplía los horizontes de la teoría y reconfigura el vínculo educador-educando, educando-educador, en la situación concreta en la que éste se produce, mediado por una forma particular de intervención e intención.

Este caudal de voces, reflexiones y encuentros ha permitido acercar mundos, lenguas, regiones, vivencias, visiones e historias que, al trastocar fronteras - regionales, institucionales, disciplinarias, espaciales, temporales- hace que la historia cumpla con su cometido de engarzar la memoria con la mirada puesta en lo posible. Así, en las luchas de los pueblos por la emancipación, la justicia y la igualdad, las experiencias político-pedagógicas construidas para reconfigurar las tramas de la opresión encuentran, en el ethos de las pedagogías populares, críticas, de la resistencia y de la esperanza, un camino en el que la obra freireana se reinventa en la polifonía de voces que le dan vida. Y estas voces, a su vez, hacen que en el cometido ético-político de la liberación esta obra no se pierda de vista; que, en el encuentro dialógico y problematizador con el otro, algo nuevo o diferente se 
construya como horizonte de posibilidad. Porque, cuando la palabra vinculada con la práctica, la cultura, la vivencia, el diálogo, el acontecimiento, el territorio y el conocimiento encuentra su razón de ser, abre la posibilidad de nombrar y visibilizar lo que, estando ahí, no se había reconocido como propio. Lo anterior tiene un significado especial en los sujetos, particularmente en quienes, al vivir una condición de opresión, no se reconocen como constructores de realidad; al no ser nombrada y representada esta realidad, difícilmente se trastocarán los umbrales de la opresión.

Ese pasaje que Freire recrea en Cartas a quien pretende enseñar (2019 [1994]) con el cuidado que demanda la reflexión crítica sobre la enseñanza y sobre el papel del educador y la educadora popular, condensa los alcances de un proceso de desvelamiento de la realidad en el que la teoría "emerge empapada en su práctica", como nuestro autor ha dejado inscrito en su "Primera carta: Enseñar a aprender. Lectura del mundo-lectura de la palabra” (Freire, 2019).

Freire narra que en una tarde de capacitación, durante la discusión acerca de una fotografía que retrataba a Porto Mont con sus casitas alineadas a la orilla dela playa frente al mar, donde se veía también un pescador que desembarcaba con un pescado en la mano, dos de los participantes se levantaron como si se hubiesen puesto de acuerdo, caminaron hasta una ventana de la escuela y, mirando Porto Mont allá a lo lejos, dijeron, volviéndose nuevamente hacia la imagen que representaba al pueblo "Sí, Porto Mont es exactamente así, y nosotros no lo sabíamos" (Freire, 2019: 51). "Inmersos en la realidad de su pequeño mundo, no eran capaces de ver; 'tomando distancia' de aquélla, emergieron y así, vieron como jamás habían visto hasta entonces" (Freire, 2019: 52).

\section{TOMAR DISTANCIA, AVENTURARSE A LO POSIBLE}

La dimensión político-pedagógica, epistemológica y gnoseológica configura, así, un entramado que, en las circunstancias particulares en las que se produce y construye el encuentro con el otro, plantea, entre otras dimensiones, que Paulo Freire configuró como base de su ideario como educador, ubicar el papel que adquieren ciertas cuestiones en la cotidianeidad (como la problematización, la formulación de preguntas, la crítica, las decodificaciones, los sentimientos, las creencias, las vivencias, los valores, lo sensible y lo que el deseo anima a nombrar a sabiendas de la imposibilidad de su realización), las cuales influyen en las relaciones que se producen entre el educador, el educando y los saberes que se aprehenden, resignifican, crean y recrean en espacios y momentos concretos, mediados por la acción-reflexión (Freire, 1980).

Este encuentro con el otro se da mediado por la palabra, el diálogo y el quehacer crítico que conlleva una forma de intervención particular cuando lo que está en juego es tomar distancia de las determinaciones que dificultan, opacan o impiden ver más allá de la inmediatez de lo que se vive e interioriza como dado.

Lo anterior plantea, entre otras cuestiones, el problema de pensar las articulaciones posibles y deseables entre experiencia, vida cotidiana y saber; 
entre los conceptos creados en el mundo de la experiencia sensorial y aquéllos que se construyen en el ir y venir de la investigación. Implica que los sujetos participantes en un determinado entramado pedagógico, dialógico, crítico y problematizador, se arriesguen, se aventuren a lo posible, a lo desconocido; a aquello que, como invención, abre las posibilidades de la creación que la praxis plantea como síntesis entre teoría-palabra y acción; en palabras de Rossato (2015: 408): "hay un vínculo estrecho entre pensar - decir la palabra - y la acción".

Freire fue contundente al respecto:

Al estudio crítico corresponde una enseñanza también crítica, que necesariamente requiere una forma crítica de comprender y de realizar la lectura de la palabra y la lectura del mundo, la lectura del texto y la lectura del contexto... Decir la palabra es definir el lugar del ser humano en el mundo, lo cual no excluye ninguna de las dos formas de lenguaje o de sintaxis (Freire, 2019: 52).

Lo anterior imbrica en el ejercicio mismo de la aprehensión problemática y crítica de la realidad y del conocimiento; de aquello que forma parte del mundo de la experiencia, del saber hecho experiencia, así como de lo que se construye a partir de otros planos de elaboración conceptual que requieren, a su vez, ser puestos en cuestión para no caer en la repetición, o lo que, en palabras de Boaventura de Souza Santos (2010), podríamos señalar como la colonización del saber.

La vivencia o experiencia existencial se convierte en mediación pedagógica que lanza a los educandos(as) al análisis de los problemas y propicia condiciones de una verdadera participación. Todo esto pasa por la mediación intrínseca que constituyen las diversas tramas, "el cuerpo mojado" de nuestra historia, de nuestra cultura. Consecuentemente, Freire comprendió - como lo precisa Adams- "que las mediaciones de la pedagogía del oprimido pasan por la lectura y escritura de la palabra, en la medida que la escritura implica una relectura crítica del mundo" (Adams, 2015: 324).

Los conceptos o nociones que se configuran en este proceso alcanzan una operación epistemológica y gnoseológica que define, como eje articulador de lo simbólico y de lo ideológico, un referencial teórico-conceptual que, por nacer de la experiencia, les permite a los sectores involucrados, dentro y fuera de las instituciones, fundamentar el conjunto de los argumentos y horizontes de sentido que sustentan su proyecto político-pedagógico y el tipo de sujetos que se constituye en este proceso. Asimismo, la posición de los actores involucrados se redimensiona y los sitúa como sujetos educativos, constructores de conocimiento, a la vez que refuerza sus identidades socioculturales y políticas, en diálogo con el mundo: "nadie educa a nadie — nadie se educa a sí mismo—, los hombres [y las mujeres, agregaríamos] se educan entre sí con la mediación del mundo" (Freire, 1970: 69).

En este sentido, la experiencia puede constituirse como lugar de construcción de una otra episteme, elemento fundamental en la conformación de proyectos alternativos; una episteme que es base para diferenciar la 
racionalidad científica-tecnológica de otras relacionadas con la historia de los pueblos y con su legado cultural. A decir de Pinheiro:

Una episteme que nos posibilite hacer de la experiencia un a priori en la contextualización y problematización de lo social, de lo político, de lo cultural; que exprese los horizontes de sentido conferidos a las inquietudes que emergen de la labor cotidiana, haciendo explícita la intrínseca relación entre los sentidos atribuidos a la lucha y gestación de un proyecto de sociedad alternativo (Pinheiro, 2013: 123).

Obviamente, ello implica retos para que se avance en la materialización de un proyecto político de carácter emancipatorio, por lo que uno de los principales desafíos se relaciona con pensar los alcances y límites que tiene una determinada propuesta pedagógica en la conformación y potenciación de un proyecto político-social democrático y popular. Esperanza, resistencia y praxis transformadora se articulan en la construcción de proyectos que no sólo se basan en la experiencia que se configura en el marco de las luchas de los pueblos por la justicia, los derechos y la igualdad, así como en lo cotidiano, porque es ahí donde se gestan y construyen las bases de los grandes procesos de transformación; estos proyectos también se configuran en la relación educador-educando, educando-educador, para poder encarar, desde lo colectivo, las huellas o rastros que la opresión deja inscritos, de múltiples maneras, en la vida de las personas.

\section{Y, ¿LA ESPERANZA?}

La palabra esperanza parece no encontrar refugio cuando lo que está en juego no es una cuestión ajena a la historia y a quienes, en su nombre, le dan la espalda a la injusticia o a las ruinas de un pasado que se derrumba inexorablemente ante nuestros ojos. Cuando la visión de los "vencidos", la palabra de los oprimidos irrumpe cargada de sentido, algo de lo que fue negado, desconocido, borrado, reprimido o invisibilizado altera la racionalidad que subyace a las lógicas del poder que buscan estandarizar, regular, controlar u homogenizar - a partir de ciertos dispositivos culturales e institucionales"las gramáticas" (Saur, 2008: 69) en las que se fundamentan y configuran mentalidades que se estructuran desde la lógica del discurso de la opresión.

Como señala Benjamin, si la historia fuera contada por los vencidos, la alegre cadena del progreso daría un vuelco, llegando a subvertir el relato oficial. Lo que para la historiografía convencional ha sido una simple excepción se constituiría como la auténtica regla de la historia (Santos, 2009: 158).

La esperanza no es cuestión de cálculo, pues no se trata de prefigurar acontecimientos seguros que vayan a ocurrir inexorablemente; es una cierta apuesta que hace que sea razonable confiar en que el opresor no tendrá la última palabra sobre el oprimido. Y, con el arrojo con el que la inteligencia 
embiste al coraje de la lucha y el compromiso, Freire nos interpela al marcar con contundencia que

Pensar que la esperanza sola transforma el mundo y actuar movido por esa ingenuidad es un modo excelente de caer en la desesperanza, en el pesimismo, en el fanatismo. Pero prescindir de la esperanza en la lucha por mejorar el mundo, como si la lucha pudiera reducirse a actos calculados, a la pura cientificidad, es frívola ilusión (Freire, 1993: 8).

Con Freire hemos aprendido que la condición de opresión no sólo está relacionada con las condiciones concretas, objetivas y subjetivas en las que encarnan la injusticia y la desigualdad de un sistema-mundo que ha fincado su razón de ser en la concentración, el lucro, la explotación, la exclusión, el racismo, la dominación y la muerte (Jiménez, y Valle, 2020); también está relacionada con las luchas de los pueblos por acceder a condiciones de vida dignas y por constituirse en sujetos que, vinculados con movimientos y acciones concretas, marquen otros rumbos a la historia y generen propuestas que, además de responder a necesidades y demandas específicas, brinden bases para resistir y generar proyectos alternativos que abonen a los procesos de transformación social, cultural y económica. El rescate que hace Freire de la política es, y sigue siendo, una dimensión central que articula el conjunto de su obra, ya que la concibe como "el elemento más dinámico de la cultura”; a la política se articula la educación al estimular los movimientos de liberación. "Esa posición respecto de la política - destaca Puiggrósle dio a Freire la posibilidad, que aún conserva, de incidir en la transformación de la educación latinoamericana” (Puiggrós, 2005: 25).

Pensar la esperanza en su relación con la educación, la política y la cultura exige reconocer las huellas profundas que la opresión inscribe en la mentalidad, en los cuerpos y en las formas de relación e interacción de los sujetos con el saber; y, finalmente, con todo aquello que involucre alguna relación de opresión y dominación, sea de carácter social, comunitario, institucional, y hoy podríamos agregar, virtual. Por ello, la finalidad es apropiarse críticamente de la cultura dominante para liberarse de ella a partir de una vinculación dialógica entre culturas. En la emergencia de ésta y otras situaciones se configuran espacios de acción y de organización.

Lidia Rodríguez abre una reflexión importante al señalar que:

...a mediados del siglo XX se desarrolló en América Latina una corriente de la educación que se conoce como "alternativas pedagógicas" o de "educación popular", y cuya figura más sobresaliente es Paulo Freire. Esa propuesta acompañó los proyectos de transformación de distintas sociedades y construyó el sujeto pedagógico latinoamericano: el oprimido (Rodríguez, 2015: 89).

La esperanza, en cuanto necesidad ontológica, necesita de la práctica para resolverse historia concreta. Es la "experiencia de una espera incierta", como afirma Bordelois (2006: 174), frente a una situación límite, cuando se 
articula con lo posible, con la imaginación, con el horizonte utópico que conlleva un proyecto de praxis y de transformación.

Por ello, "... la lucha que hacemos, movidos por la esperanza, por el fundamento ético-histórico de su acierto, forma parte de la naturaleza pedagógica del proceso político del que esa lucha es expresión" (Freire, 1993: 9).

\section{AMÉRICA LATINA: SITUACIÓN LÍMITE, ESPERANZA Y POSIBLES ARTICULACIONES POLÍTICO-PEDAGÓGICAS}

Sin desconocer las profundas implicaciones ético-políticas que tiene esta dimensión de la reflexión y la acción, nos interesa marcar, como itinerario para el diálogo, el registro de lo pedagógico, ya que en él está implicado un ángulo de lectura que no es ajeno a la condición de vida de la gente, a su dolor, sus sueños, sus luchas; a sus rutinas, inercias, miedos y soledades; a los vínculos que construye en su relación y diferencia con el otro; a la vida cotidiana que, cruzada por los pequeños y grandes acontecimientos define, en parte, la historia de las personas, los grupos, las comunidades, las instituciones y las sociedades. Lo pedagógico comprende, también, los rastros que quedan cuando en su paso por la vida alguien se enfrenta a la parte más siniestra del poder, aquélla que busca acallar los reclamos de justicia con la imagen terrorífica de la crueldad, la desesperanza, la injusticia y el dolor de unos, que es de todos, y que coloca a las personas frente a situaciones límite en las que anida la desesperanza.

En palabras de Freire: "en las situaciones límite, más allá de las cuales se encuentra lo 'inédito viable', a veces perceptible, a veces no, se encuentran razones de ser para ambas posiciones: la esperanza y la desesperanza' (Freire, 1993: 9). Su compleja e incierta articulación con el sueño del educador, con las opciones viables y posibles, no siempre visibles, pero que se encuentran presentes en los distintos niveles de la sociedad (particularmente aquéllos que se sitúan en el nivel de lo local, de la coyuntura y de la microsituación), abre la posibilidad para que el trabajo de intervención política, con la amorocidad y rabia que acompañan la esperanza, esperanzada, "permita el reconocimiento de los inéditos viables superadores de la situación límite"; esta dimensión, desde la perspectiva freireana, probablemente es "una de las cuestiones más importantes de la tarea pedagógica” (Rodríguez, 2015: 161).

La educación popular y las alternativas pedagógicas que diversos sectores han producido en América Latina y el Caribe en diferentes situaciones y momentos de la educación de nuestro continente (Rodríguez, 2013a; Puiggrós, 2005; Gómez Sollano y Puiggrós, 2019) condesan, en parte, este proceso. Frente a situaciones límite, los educadores y educadoras populares han hecho de la imaginación pedagógica y de la praxis una condición que dota de sentido a la acción y a la reflexión crítica, "en el sueño posible y en la utopía que vendrá” (Araújo, 1993: 194).

El carácter dislocador y articulador que la obra de Paulo Freire tiene en este proceso es central; hay que ubicarla como parte de un proceso histórico que recorre la pedagogía latinoamericana en la que se condensa, como 
una de sus expresiones, lo que Adriana Puiggrós distinguió, a principios de los ochenta, como una educación popular bancaria y autoritaria y otra dialógica y democrática. Concibió a la educación popular como "aquélla que tiene como sujetos participantes centrales a los sectores oprimidos y desposeídos de la sociedad, y como educadores a sectores que expresan proyectos de transformación social" (Puiggrós, 1982: 2), con las implicaciones éticas, políticas, sociales, culturales y pedagógicas que esto tiene para la formación de las personas, la conformación de sus espacios de acción y la producción de conocimientos.

Por otra parte, se reconoce que uno de los propósitos centrales del debate sobre las educaciones populares es la cuestión de la transformación de la sociedad. Esto implica que la acción educativa está dirigida por $-\mathrm{y}$ cobra sentido en - el actuar cotidiano de los sectores populares, y que no comprende solamente procesos educativos instrumentales, sino que articula los elementos educativos que requiere el avance de las organizaciones populares. Por ello, una de las características más importantes de la educación popular la constituye su intencionalidad política, que se expresa como voluntad de transformación de lo real a partir de condiciones dadas, a partir del diseño de estrategias y tácticas que adquieren su sentido y legibilidad cuando son incorporadas a las luchas del pueblo.

En este sentido, la educación popular involucra siempre una posición política y político-pedagógica, un compromiso con el pueblo frente al conjunto de su educación; no se reduce a una acción centrada en una modalidad educativa, como la educación no formal, o a un recorte de los sectores populares, como podrían ser los marginados, o a un grupo generacional, como los adultos, o a una estrategia determinada, como la alfabetización rural. Debe atravesar todos los niveles del sistema de educación formal y los espacios de educación no formal como posición de defensa de los intereses populares, como productora de modelos, saberes, estrategias, contenidos y metodologías democráticas de educación; como instrumento de lucha en un campo tan plagado de diferencias y articulaciones como es el educacional. En la base de todos estos procesos está presente la intencionalidad e implicaciones educativas y de comprensión-acción-transformación de la realidad.

Desde el punto de vista educativo se trata de un proceso que exige la generación de prácticas y saberes que permitan el análisis crítico y problematizador de la realidad social, la acción colectiva y el desarrollo de valores sociales democráticos. Conciencia, conocimiento y reflexión; transformación de las actitudes y de lo real; avance sistemático en la comprensión del mundo desde los intereses y necesidades concretos de la población, forman parte del ideario pedagógico del que se han nutrido las visiones de educación popular a lo largo de su historia.

En el marco de esta diversidad de enfoques, existe consenso en aceptar como rasgos comunes de la educación popular, entre otros: su carácter pedagógico-político; su sentido popular respecto de los sujetos de su acción (sectores populares) y sus objetivos (instrumento de apoyo a la organización popular y a la construcción de su proyecto político social); 
las dimensiones cognitiva (objetivación colectiva y crítica de la realidad) y de transformación de sus prácticas; y la centralidad de la participación, la integralidad, la continuidad y la sistematización crítica, implícita en la implementación de sus acciones.

En la década de los sesenta, a partir de la II Conferencia General del Episcopado Latinoamericano de Medellín, Colombia (1968) y del comienzo de la experiencia brasileña de Paulo Freire se comenzó a utilizar el concepto de educación popular como equivalente al de educación de los oprimidos. Se desarrolló una serie de modelos dialógicos que buscaban la democratización del proceso de enseñanza-aprendizaje, así como de modelos político-académicos. Desde esta nueva corriente, denominada pedagogía de la liberación, se identificó generalmente a la educación popular con la educación rural de adultos analfabetos y, algunas veces, con alfabetización. Otras definiciones de educación popular se hicieron extensivas a difusión cultural, diversos tipos de desarrollo comunitario, catequización de sectores populares, educación de sectores marginales, etc.

A fines de los ochenta comenzó a producirse un desplazamiento de gran parte de las experiencias de educación popular desde el campo revolucionario tradicional hacia un nuevo campo problemático, el de la defensa de los derechos humanos, donde se ubicaron problemáticas que en las décadas anteriores habían quedado opacadas por la fuerza de los discursos políticodoctrinarios. Las problemáticas de la mujer, los indígenas, los niños, los refugiados, los grupos barriales y municipales, así como las de algunos sectores generacionales, migrantes y otros despuntaron como síntoma de un proceso de constitución de nuevos sujetos políticos que pertenecían a sectores socialmente oprimidos desde antaño, pero que carecían de voz propia en los discursos maximalistas del siglo. Entre sus derechos humanos, derechos del pueblo, comenzaron a expresar su demanda por tener poder como educandos y como educadores. La incorporación a la legislación de la categoría "derecho a la educación” en varios países constituyó un cambio cualitativo. La educación popular, desde todas sus tendencias, no pudo ser ajena a la necesidad de volver a pensar en sus sujetos, así como en el tipo de saberes y experiencias que producen. Al surgimiento de los nuevos sujetos debe sumarse la fractura que han ido sufriendo los sistemas escolares y que plantea nuevos retos a la educación popular. Lejos de haber perdido su vigencia, el significante "educación popular" vuelve a estar disponible para nombrar alguna novedad del orden de las alternativas; un uso con multiplicidad de sentidos y una disputa por su apropiación (Rodríguez, 2013b).

\section{DE LA RELECTURA A LA REINVENCIÓN DE LA OBRA FREIREANA}

La relectura y reinvención de la obra freireana adquiere un lugar central en el entramado político-pedagógico de la historia de la educación latinoamericana porque ha acompañado, al menos en parte, los procesos de transformación en la región. 
La Pedagogía de la esperanza (1993) es un libro escrito con rabia y con amor, sin lo cual no hay esperanza. Las últimas palabras con las que Freire cierra su Pedagogía del oprimido expresan la posibilidad de ese reencuentro crítico y problematizador con toda una experiencia de vida y de compromiso ético, político y pedagógico con el que este pensador acompañó su ideario de vida, de acción y reflexión crítica:

Si nada queda de estas páginas, esperamos que por lo menos algo permanezca: nuestra confianza en el pueblo. Nuestra fe en los hombres y en la creación de un mundo en que sea menos difícil amar. Difícil, pero no imposible tarea, cuando las tramas de la vida terminaron por traerme al exilio al que llego con el cuerpo mojado de historia, de marcas culturales, de recuerdos, de sentimientos, de dudas, de sueños rotos, pero no deshechos, de nostalgias de mi mundo, de mi cielo, de las aguas tibias del Atlántico, de la "lengua errada del pueblo, lengua acertada del pueblo". Llegué al exilio y a la memoria de tantas tramas que traía en el cuerpo y añadí la marca de nuevos hechos, nuevos saberes que se constituían entonces en nuevas tramas (Freire, 1993: 10).

Volver la mirada al legado teórico-epistemológico, político-pedagógico, humanístico y cultural que Freire configuró a través de su obra y su praxis es vital para que el miedo no mate a la esperanza de lo que significa encarar con inteligencia y valentía aquello que el educador de la praxis soñó y por lo que tanto luchó.

Abrir la puerta a la historia para recrear territorios a partir del ejercicio iniciado por Paulo Freire hace más de ocho décadas y miles de sueños brinda una base para articular la educación con ese acto de amorosidad, compromiso y responsabilidad que todo vínculo pedagógico, dialógico y crítico exige, sobre todo frente a las situaciones límite; en éstas, el educador y la educadora, con su intervención, pueden crear condiciones para potenciar la esperanza que nos permita aprender a vivir entre tiempos, en el devenir de lo posible como proyecto, donde necesidad y deseo no sucumban ante el porvenir por el que transitan los pueblos de esta nuestra América, "...que acaso sea esto solamente: tensión, expansión y crecimiento constante - como el espacio mismo-. Como la esperanza”. Pero para que la esperanza no se deje atrapar por el delirio, "es necesario que el amor amanezca posible" (Thiago de Mello).

La política, la filosofía, la historia y la pedagogía amplían sus horizontes cuando voltean la mirada a las prácticas culturales que subvierten de manera constante ese orden discursivo que busca regular y controlar nuestra comprensión de lo real: desregulan lo que parecía una relación fija entre lo real y sus simulacros; reconstituyen campos de identidad y diferencia; ponen a prueba las llamadas representaciones auténticas de la "verdad" frente a las reconstrucciones creativas. Así, estas intervenciones construyen comunidades alternativas de conocimiento y acción que sobrepasan las propuestas más habituales de la opresión y la dominación. En este sentido, pueden jugar como tensiones o "líneas de fuga" - en el sentido en que 
Benjamin las enunció, esto es, como las líneas que separan el presente del pasado- que definen caminos para reconsiderar las prácticas y las formas sociales de su regulación. De entre ellas la educación, por el importante lugar que ocupa, requiere nutrir sus saberes y prácticas de todo el instrumental que le posibilite dotar a los sujetos de las herramientas que les permitan construir y afianzar su lazo con la vida, para sostener el mundo; por eso su tarea se inscribe siempre en un horizonte, porque vivir es inventar, inventar lo que no estando hace posible el por-venir. Freire no sólo lo supo bien. Lo asumió con valentía, humildad e inteligencia crítica... y luchó por ello.

\section{REFERENCIAS}

Adams, Telmo (2015), “Mediación (pedagógica)", en Danilo R. Streck, Euclides Redin y Jaime José Zitkoski (orgs.), Diccionario Paulo Freire, Lima, CEAAL, pp. 323-324.

Araújo Freire, Ana Maria (1993), "Notas", en Paulo Freire, Pedagogía de la esperanza, México, Siglo XXI, pp. 192-226.

Bordelois, Ivonne (2006), Etimología de las pasiones, Buenos Aires, Libros del Zorzal.

Cabaluz, Fabián, Luis Arnanz, Fernando Santana y Mariano Suárez (eds.) (2021), Paulo Freire, 100 años. Pasado y presente de una pedagogía liberadora. Paulo Freire: travesía de un pensamiento vivo. Segunda Parte, Buenos Aires, CLACSO, Col. Boletines de los Grupos de Trabajo, No. 2.

De Souza Santos, Boaventura (2010), Decolonizar el saber, reinventar el poder, Montevideo, Trilce/Universidad de la República de Uruguay-Extensión Universitaria.

Freire, Paulo (1980), "La concepción 'bancaria' de la educación y la deshumanización. La concepción problematizadora de la educación y la humanización", Carlos Alberto Torres (comp.), Paulo Freire. Educación y concientización, Salamanca (España), Sígueme, pp. 51-59.

Freire Paulo (1970), Pedagogía del oprimido, México, Siglo XXI.

Freire Paulo (1993), Pedagogía de la esperanza, México, Siglo XXI.

Freire, Paulo (2019), Cartas a quien pretende enseñar, México, Siglo XXI.

Gómez Sollano, Marcela y Adriana Puiggrós (2019), Fuentes sobre alternativas pedagógicas populares en América Latina, Buenos Aires, Universidad de Buenos Aires-Facultad de Filosofía y Letras, col. Reediciones Imprescindibles.

Jiménez, Marco y Ana María Valle (eds.) (2020), Justica y prácticas culturales contemporáneas. Figuras del pensamiento sobre lo social, México, UNAM-Facultad de Estudios Superiores Acatlán.

Pinheiro, Lía (2013), "Los movimientos sociales como sujetos educativo-políticos", en Marcela Gómez Sollano y Martha Corenstein Zaslav (coords.), Reconfiguración de lo educativo en América Latina. Experiencias pedagógicas alternativas, México, UNAM-Facultad de Filosofía y Letras-Dirección de Asuntos del Personal Académico, col. Seminarios, pp. 121-162.

Puiggrós, Adriana (1982), "Elementos para una historia de la educación de adultos en la Argentina. Proyecto APPeAL", Buenos Aires, CONACyT/UNAM/CONICET/ UBA, mimeo.

Puiggrós, Adriana (2005), De Simón Rodríguez a Paulo Freire. Educación para la integración iberoamericana, Bogotá, Convenio Andrés Bello.

Rodríguez, Lidia (dir.) (2013a), Educación popular en la historia reciente en Argentina y América Latina. Aporte para balance y prospectiva, Buenos Aires, Universidad de Buenos Aires-Facultad de Filosofía y Letras/APPeAL.

RodríGuez, Lidia (2013b), "La elección categorial: alternativas y educación popular", en Lidia Rodríguez (dir.), Educación popular en la historia reciente en Argentina y América Latina. Aporte para balance y prospectiva, Buenos Aires, Universidad de Buenos Aires-Facultad de Filosofía y Letras/APPeAL, pp. 25-40. 
Rodríguez, Lidia (2015), Paulo Freire. Una biografía intelectual. Surgimiento y maduración de la pedagogía del oprimido, Buenos Aires, Colihue, col. Alternativa Pedagógica, Historia.

Rossato, Ricardo (2015), "Praxis”, en Danilo Streck, Euclides Redin y Jaime José Zitkoski (orgs.), Diccionario Paulo Freire, Lima, CEAAL, pp. 407-409.

Santos, Marco Antonio (2009), "Los oprimidos como luz. Benjamin, Kafka, teología de la liberación", Revista de Filosofía, vol. 34, núm. 2, pp. 157-174.

SAUR, Daniel (2008), "Categorías intermedias y producción de conocimiento", en Eva da Porta y Daniel Saur (coords.), Giros teóricos en las ciencias sociales y las humanidades, Córdoba (Argentina), Secretaría de Ciencia y Técnica/FONCYT/ Universidad Nacional de Córdoba-Centro de Estudios Avanzados, pp. 63-71. 